\title{
The role of performance measure characteristics in the design of incentive systems: an empirical analysis
}

Citation for published version (APA):

Moers, F. (2000). The role of performance measure characteristics in the design of incentive systems: an empirical analysis. METEOR, Maastricht University School of Business and Economics. METEOR Research Memorandum No. 052 https://doi.org/10.26481/umamet.2000052

Document status and date:

Published: 01/01/2000

DOI:

10.26481/umamet.2000052

Document Version:

Publisher's PDF, also known as Version of record

\section{Please check the document version of this publication:}

- A submitted manuscript is the version of the article upon submission and before peer-review. There can be important differences between the submitted version and the official published version of record.

People interested in the research are advised to contact the author for the final version of the publication, or visit the DOI to the publisher's website.

- The final author version and the galley proof are versions of the publication after peer review.

- The final published version features the final layout of the paper including the volume, issue and page numbers.

Link to publication

\footnotetext{
General rights rights.

- You may freely distribute the URL identifying the publication in the public portal. please follow below link for the End User Agreement:

www.umlib.nl/taverne-license

Take down policy

If you believe that this document breaches copyright please contact us at:

repository@maastrichtuniversity.nl

providing details and we will investigate your claim.
}

Copyright and moral rights for the publications made accessible in the public portal are retained by the authors and/or other copyright owners and it is a condition of accessing publications that users recognise and abide by the legal requirements associated with these

- Users may download and print one copy of any publication from the public portal for the purpose of private study or research.

- You may not further distribute the material or use it for any profit-making activity or commercial gain

If the publication is distributed under the terms of Article $25 \mathrm{fa}$ of the Dutch Copyright Act, indicated by the "Taverne" license above, 
The Role of Performance Measure Characteristics in the

Design of Incentive Systems: An Empirical Analysis*

\author{
Frank Moers
}

\author{
Maastricht University \\ Faculty of Economics and Business Administration \\ MARC / Department of Accounting \& Auditing \\ P.O. Box 616 \\ 6200 MD Maastricht \\ The Netherlands \\ f.moers@berfin.unimaas.nl
}

MARC Working Paper
MARC-WP/3/2000-14

*I gratefully appreciate the comments made by my thesis advisors Willem Buijink, Frank Hartmann, and Ken Merchant. I am further grateful to Chris Ittner, Erik Peek, Mike Shields, and Wim Van der Stede for their comments and discussions. This paper has been presented at the Empirical Accounting Research Seminar at Nijenrode University and the accounting seminar at Maastricht University. 


\section{INTRODUCTION}

The study of incentives is one of the most important areas in accounting research. This topic has received a considerable amount of attention from both the economics-based literature and the behavioral-based literature. Although both literatures study the same type of problem, though in different ways, there is almost no cross-fertilization (Merchant et al. 2000). This paper answers to the recent calls for more integration (e.g., Atkinson et al. 1997; Merchant et al. 2000) and combines insights from the economics-based literature and the behavioral-based literature to study the role of performance measure characteristics in the design of incentive systems for subordinate managers.

In this paper, I derive three general performance measure characteristics from the literature that are theoretically related to the use of performance measures, i.e., (1) the impact that a manager has on performance (sensitivity), (2) the impact that uncontrollable factors have on performance (controllability), and (3) the degree to which the performance measure is objective and verifiable (measurement accuracy). I empirically examine the effect of information asymmetry and the performance measure characteristics on the use of three types of performance measures: (1) financial, (2) internal non-financial, and (3) external nonfinancial. Furthermore, I examine how two types of uncertainty, i.e., task uncertainty and environmental uncertainty, affect the performance measure characteristics.

There are three reasons for focusing on information asymmetry, performance measure characteristics and uncertainty. First, the type of incentives used depends on the level of information asymmetry, where increased information asymmetry increases the need for output measurement, which is the focus of this paper. Second, performance measure characteristics, such as sensitivity and controllability, underlie most predictions in incentive studies in accounting. Although the theoretical predictions are based on performance measure characteristics, no structured attempt has been made so far to actually incorporate these 
characteristics in empirical research. Third, uncertainty is the core concept upon which organizational design frameworks are based (Galbraith 1977). Hartmann (2000) states that uncertainty is the underlying variable of most empirical studies investigating the use and effects of financial performance measures. Furthermore, he states that the effects of uncertainty are not well-understood (Hartmann 2000, 471).

The empirical results show that sensitivity is positively related to the use of all three types of performance measures, while measurement accuracy is positively related to the use of financial and internal non-financial performance measures. Controllability, on the other hand, does not have the proposed positive effect on any of the performance measures. These results suggest that sensitivity and measurement accuracy play an important role in designing incentive systems, while controllability seems to play no role. The empirical results further indicate that decision-making authority, as a proxy for information asymmetry, is only positively related to the use of financial performance measures. Regarding the effect of uncertainty, the results show that task uncertainty increases the sensitivity of financial and internal non-financial performance measures, but is not related to the sensitivity of external non-financial performance measures. Finally, environmental uncertainty decreases the controllability of all three types of performance measures.

This paper contributes to the literature in four ways. First, it attempts to measure performance measure characteristics and empirically examine how these affect the use of performance measures. Second, this study simultaneously investigates the use of performance measure of both a financial and non-financial nature. Third, it examines how different types of uncertainty affect the characteristics of performance measures. Finally, it integrates findings from both the economics-based literature and the behavioral-based literature to provide a more complete analysis. 
The remainder of this paper is organized as follows. Section II presents the theoretical analysis and the development of hypotheses. Section III describes the sample selection and data collection. The empirical results are discussed in Section IV. Finally, Section V provides a summary and conclusion.

\section{THEORY AND HYPOTHESIS DEVELOPMENT}

Both the economics-based literature and the behavioral-based literature either explicitly or implicitly state that performance measure characteristics should explain the use of performance measures and that performance measures should be used when behavior cannot be observed or measured. In this paper, I focus on three types of performance measures: (1) financial performance measures, (2) internal non-financial performance measures, and (3) external non-financial performance measures. This classification is partly based on the literature (e.g., Larcker 1981; Gordon and Narayanan 1984; Ittner et al. 1997) and partly on the interviews with human resource managers of the firms participating in this study. First, the financial performance measures are defined as the 'traditional' financial performance measures, such as return-on-assets, net income, and cash flows. ${ }^{1}$ Second, the internal non-financial performance measures consist of performance measures that are directly related to the tasks performed. Examples of these performance measures are productivity, efficiency, and successful implementation of projects. Finally, the external nonfinancial performance measures are defined as those performance measures that reflect performance in the market. Examples of these performance measures are market share, market growth, and customer satisfaction.

\section{Information asymmetry (decision-making authority)}

The reason why firm design compensation contracts based on performance measures instead of on managerial actions is because managerial actions cannot be observed, they are too costly to observe, or because superiors cannot interpret what they are observing. This 
information asymmetry due to the 'unobservability' of managerial actions increases the need for performance measures. Information asymmetry occurs when decision rights are allocated downward in the organization, i.e., decision-making authority is decentralized. This increase in decision-making authority creates a need to evaluate the outcomes of the decisions made lower in the organization. Decision-making authority, as a proxy for information asymmetry, will therefore lead to demand for performance measurement and the use of any feasible performance measures available. However, increased decision-making authority also increases the demand for more aggregate information (Chenhall and Morris 1986). Providing managers with more decision-making authority means that managers will take more actions, which results in increases in information asymmetry. Since it is too costly to have performance measures for each type of action (Banker and Datar 1989; Ittner and Larcker 1999), there exists an increased preference for more aggregate performance measures, i.e., performance measures that provide (some) information about an increased 'number' of actions. Financial performance measures are more aggregate than both internal and external non-financial performance measures, since the outcomes of all actions finally need to end up in the financial results. This means the usefulness of financial performance measures increases, while the usefulness of the non-financial performance measures decreases as decision-making authority increases. As a result, information asymmetry has a differential effect on the use of the three types of performance measures. The existence of information asymmetry due to the allocation of decision rights has a positive effect on the use of all three types of performance measures, while the need for aggregation due to increased information asymmetry has a positive effect on the use of financial performance measures and a negative effect on the use of internal and external non-financial performance measures. Because it is unclear a priori whether the 'information asymmetry aspect' or the 'aggregation aspect' will 
dominate, no directional hypotheses can be stated with respect to the non-financial performance measures. The above arguments lead to hypotheses 1a-1c.

Hla: Decision-making authority increases the use of financial performance measures.

H1b: Decision-making authority is not related to the use of internal non-financial performance measures.

H1c: Decision-making authority is not related to the use of external non-financial performance measures.

\section{Performance measure characteristics}

Previous studies have used a multitude of performance measure characteristics in developing hypotheses. Most of the economics-based empirical research (e.g., Lambert and Larcker 1987; Sloan 1993) has been founded on the informativeness principle of Holmström (1979) and the extensions made in the accounting literature by Banker and Datar (1989) and Feltham and Xie (1994). Holmström (1979) finds that any performance measure that is available at no cost should be used for incentive purposes if it is informative. That is, if a performance measure provides (incremental) information about the decisions made by the manager, it should be used in the evaluation of that manager. Although Holmström's finding gives an indication of what performance measures should be used, it does not provide an answer to the question of how much weight to put on each performance measure. Banker and Datar (1989) extend the results by Holmström and analytically show that the weight put on a performance measure depends on the sensitivity and noise of the performance measure. Sensitivity is formally defined as the marginal contribution of the manager's actions to the expected outcome of a performance measure. Noise, on the other hand, is formally defined as the variance in the actual outcome of the performance measure due to 'random events'. Obviously, these characteristics have a specific meaning in principal-agent models. However, 
intuitively sensitivity relates to the degree to which a manager's decisions have an impact on performance, while noise relates to the degree to which uncontrollable factors have an impact on performance. Ceteris paribus, the greater the sensitivity, the more weight is put on the performance measure, while the greater the noise, the less weight is put on the performance measure.

Feltham and Xie (1994) use an agency model that incorporates an additional problem in choosing performance measures, i.e., performance measure congruence. Their results indicate that incorporating more congruent performance measures has economic value. However, as congruence is not a single parameter in their model, it is unclear how congruence affects the weight put on a performance measure.

In contrast to the economics-based empirical research, most of the behavioral-based empirical research is based on the controllability principle (e.g., Govindarajan 1984; Govindarajan and Gupta 1985). The controllability principle states that managers should only be held responsible for things they can control (Merchant 1989). That is, the manager should not be held responsible for the impact of uncontrollable factors on performance. The greater the impact of the uncontrollable factors the lower the controllability and the less emphasis is put on that particular performance measure. Although noise is specifically defined in principal-agent models, the intuitive interpretation is identical to that of controllability and both are sometimes even used as synonyms (see e.g., Merchant 1989, 87).

In an extensive field study, Merchant (1989) finds that the controllability principle is not strictly applied in practice. He concludes that the most important factor explaining the use of performance measures is the degree of influence the manager has (Merchant 1989, 106). That is, if the manager's decisions have an impact on the outcome of the performance measure, then that performance measure will be used for incentive purposes. These results are consistent with the more intuitive interpretation of sensitivity described in the principal-agent 
models. It further suggests that sensitivity and noise/controllability are two separate performance measure characteristics.

Finally, Merchant (1989) identifies a performance measure characteristic that has received almost no attention in the empirical literature, i.e., measurement accuracy. Measurement accuracy consists of two components: verifiability and objectivity. Verifiability means that the measures can be 'substantially duplicated by independent measurers using the same measurement methods' (Merchant 1989, 26), i.e., the measurement dispersion is small. Objectivity, on the other hand, means that the measurement is 'free from personal bias' (Merchant 1989, 26). Inaccurate performance measures make it more difficult to elicit the manager's performance from the measure and should therefore be used less. Notice that this prediction is identical to that with respect to the impact of uncontrollable factors. However, there is a conceptual difference between accuracy and noise or controllability in the sense that the first is due to the measurement process, while the second is due to factors affecting the day-to-day operations.

Although all of the performance measure characteristics described above are different in a strict sense, there are some important similarities. In general, a distinction can be made between (1) the impact that a manager has on performance, (2) the impact that uncontrollable factors have on performance, and (3) the degree to which the performance measure is objective and verifiable. This implies that if we move beyond strict definitions, the different characteristics reflect three general performance measure characteristics, which I label (1) sensitivity, (2) controllability, and (3) measurement accuracy.

Following the economics-based literature and the behavioral-based literature, I predict that the use of performance measures depends on the performance measures' characteristics. More specifically, sensitivity, controllability, and measurement accuracy have a positive 
effect on the use of performance measures. These predictions are summarized in hypotheses 2a-2c.

H2a: the use of financial performance measures increases with their (i) sensitivity, (ii) controllability, and (iii) measurement accuracy.

$H 2 b:$ the use of internal non-financial performance measures increases with their (i) sensitivity, (ii) controllability, and (ii) measurement accuracy.

H2c: the use of external non-financial performance measures increases with their (i) sensitivity, (ii) controllability, and (ii) measurement accuracy.

\section{Uncertainty}

Uncertainty is one of the most important variables in organizational design frameworks and it is also the dominant concept in performance evaluation and compensation research. The literature makes a distinction between two types of uncertainty based on its source, i.e., environmental uncertainty and task uncertainty (e.g., Fisher 1995; Hartmann 2000). Environmental uncertainty is defined as the uncertainty due to factors in the organization's environment, while task uncertainty is defined as the uncertainty due to the complexity and diversity of the task performed. These constructs have predominantly been used in the behavioral-based literature, although related constructs are available in the economics-based literature (Ittner and Larcker 2000). The general assumption made in the literature is that both environmental uncertainty and task uncertainty negatively affect the usefulness of financial performance measures because both types of uncertainty decrease the controllability of these measures. However, there are two problems with this assumption. First of all, empirical research has not always made a distinction between environmental uncertainty and task uncertainty (Hartmann 2000) and it is not at all clear if both types of uncertainty affect the controllability of financial performance measures. Second, an implicit assumption underlying this stream of research is that the two types of uncertainty have no 
effect or a positive effect on alternative performance measures. Below, I argue that the two types of uncertainty have an effect on different situational characteristics of financial performance measures and that these effects also partly apply to non-financial performance measures. I first discuss the effect of task uncertainty on sensitivity and subsequently the effect of environmental uncertainty on controllability.

Task uncertainty is a job characteristic that reflects the complexity and diversity of the task performed. The RAPM literature has assumed that high task uncertainty situations are, in part, characterized by an increase in the performance impact of factors beyond the control of the manager, which decreases the usefulness of (accounting) performance measures. However, I propose that this interpretation of task uncertainty is incorrect and mainly due to the literature's inability to clearly distinguish between different types of uncertainty (Hartmann 2000). 1 Increased task uncertainty indicates more uncertainty about the way in which a certain objective should be achieved. This does not mean that 'other factors' have more influence on performance, but rather that the actions chosen by managers are crucial to task performance. Locke and Latham (1990, p. 260) state that:

'...in more complex tasks, the plans, tactics, and strategies used by the individual play a larger role in task performance than they do in simpler tasks where the number of different strategies is more limited and are generally known to all performers.'

Lambert and Larcker (1995) make similar arguments in a study examining compensation contracts for senior-level hospital administrators. They state that:

'Hospitals with complex service offerings to the patient are inherently more difficult to manage. As a result, the profitability of these hospitals is more sensitive to the amount of effort provided by the hospital administrator' (emphasis added).

Thus, in more complex and diverse tasks, the manager's decisions are of greater importance to task performance. However, the degree to which task uncertainty increases the ability of 
managers to improve performance, i.e., increase sensitivity, depends on what measure of performance is used. If the performance measure is internal oriented and related to the task, the time-span between providing effort and observing performance becomes shorter, which increases the ability of managers to see how their efforts translate into performance. Related to this issue is that the ability of managers to improve performance is increased by the amount of feedback they receive. Feedback information facilitates learning and allows managers to update their strategies, which makes performance more effort-sensitive (Sprinkle 2000). As a result, task uncertainty increases the sensitivity of those performance measures that are internal oriented and for which feedback can be provided on a frequent basis. The conditions of internal orientation and provision of frequent feedback are present in the internal nonfinancial performance measures and to a lesser extent also in the financial performance measures, but are absent in the external non-financial performance measures. Therefore, task uncertainty increases the sensitivity of both financial and internal non-financial performance measures, but is not related to the sensitivity of external non-financial performance measures. These predictions are summarized in hypotheses $3 \mathrm{a}-3 \mathrm{c}$.

H3a: task uncertainty increases the sensitivity of financial performance measures.

H3b: task uncertainty increases the sensitivity of internal non-financial performance measures.

H3c: task uncertainty is not related to the sensitivity of external non-financial performance measures.

As already stated above, environmental uncertainty is assumed to decrease the usefulness of financial performance measures because it decreases the controllability of these measures. Environmental uncertainty increases the unpredictable impact of uncontrollable factors on performance, which makes it more difficult to judge ex-post whether good or bad financial performance is due to changing environmental conditions or due to managerial 
performance. Although this argument seems to be valid, there is no reason to assume that this relationship only applies to financial performance measures. It is very likely that this relationship also applies to the internal and external non-financial performance measures. For example, unpredictable changes in customers' behavior can have an uncontrollable impact on the degree to which these customers are satisfied with the firm's products and services, which might consequently affect market share. In a similar vein, technological developments and changes in suppliers' behavior can have an uncontrollable impact on the efficiency and effectiveness of the task performed. As a result, internal and external non-financial performance measures contain the same defects as financial performance measures in the sense that increased environmental uncertainty decreases the controllability of these performance measures. These predictions are summarized in hypotheses $4 \mathrm{a}-4 \mathrm{c}$.

H4a: environmental uncertainty decreases the controllability of financial performance measures.

H4b: environmental uncertainty decreases the controllability of internal nonfinancial performance measures.

H4c: environmental uncertainty decreases the controllability of external nonfinancial performance measures.

\section{RESEARCH METHOD}

To test the hypotheses developed in the previous section, I gathered data from multiple sources. The data sources used consist of interviews, questionnaires and proprietary archival data. Survey data are available for 114 managers employed in 6 firms, while proprietary data are available for 96 managers employed in 5 firms. This section presents details on the sample selection and data collection. 


\section{Sample of firms}

This paper focuses on the use of performance measures in the evaluation and compensation of managers. That is, rather than explaining why firms use incentive systems, this paper addresses which performance measures are used given the firm's trade-off to use an incentive system. As a result, eligible firms must have an incentive system in place, which renders random sampling inappropriate. In order to select the firms of interest, I used the following procedure. I contacted Hay Management Consultants (HMC) and explained the research question of this study. HMC provided a list of clients that were eligible for this study, which contained the name of the firm, name of the Human Resource Manager, firm address, and telephone number.

I called the Human Resource (HR) Managers of fifty firms to explain the research study and solicit their participation. Participation, at first, meant giving an interview. Out of the fifty firms, fifteen (30\%) agreed to an interview. Noteworthy is that the majority of the firms (17) that did not agree to participate were firms that were currently implementing a new or 'updated' variable compensation system, which they characterized as 'politically sensitive'. Other reasons for non-participation were time constraints (11), reorganizations (5), and mergers (2).

The interview with the HR managers served two purposes. First, the interview was used to get a better understanding of the performance evaluation and compensation system in place. It was important to examine if performance evaluation and compensation were an issue and to what extent variable compensation was important. This facilitated a more specific selection of firms relevant to this study. Second, the interview was used to ask the HR manager to support the research and to be its 'champion' within the firm.

During the interviews, the content of participation was discussed in more depth. I explained that participation implied (1) the selection of respondents, (2) the distribution of 
questionnaires by internal mail, (3) the attachment of a letter of endorsement by the HR manager or a higher-level official, (4) administrative support for follow-up procedures, and (5) the provision of a detailed description of the respondent's annual bonus plan. Of the fifteen firms interviewed, six declined further collaboration. The reasons why these firms did not participate were that they did not allow me to go 'into the firm' (4 firms) or that they did not have an annual bonus system ( 2 firms). Of the nine firms that agreed to participate, three requested a more tailor-made study. To assure uniformity of the research design, I decided to design a separate study for each of these firms and to exclude them from the current study. As a result, the final sample consists of six firms. Descriptive statistics are provided in Table 1.

Insert Table 1 about here

\section{Sample of respondents}

After the firms agreed to participate in the study, the HR manager of each firm selected the sample of respondents. In making the selection, the HR managers were given three criteria on which they should base their selection. First, the respondents should have managerial responsibilities, either as head of a functional department or as head of a division, business unit or something similar. To assure a minimum level of managerial responsibilities, the respondent's job design should have a weight greater than 400 Hay-points ${ }^{4}$ Second, the respondent should have an annual bonus plan. Finally, the respondent should have experienced at least one annual performance evaluation cycle.

The HR managers were asked to select as many respondents as possible within the above four constraints. The selection by the HR managers resulted in 202 managers that were asked to participate in the study. 


\section{Questionnaire design}

To maximize the response rate, I designed the questionnaire according to the guidelines of Dillman's (1978) Total Design Method. I pre-tested the questionnaire with seven academics and all six HR managers, which resulted in minor revisions of the questionnaire. Furthermore, I administered a follow-up by telephone and mail. Of the 202 questionnaires that were distributed, 114 were returned. This corresponds to an overall response rate of $56 \%$. This response rate is satisfactory and comparable to the response rates reported in previous accounting studies. Of the 114 questionnaires returned, nine have missing data. Because I use bootstrapped coefficient estimates and standard errors to calculate significance levels (Noreen 1989; Mooney and Duval 1993), I delete the nine questionnaires with missing data listwise.

As the response rate is not $100 \%$, though satisfactory, I conduct a test for non-response bias. I split the sample at the firm-specific median response time and calculate a t-test for differences in means for each of the variables of interest to this study. The results indicate that there are no significant differences between early and late respondents for any of the variables. This suggests the absence of non-response bias.

\section{Proprietary archival data}

Five firms provided archival data with respect to the annual bonus contract of the respondents, which were used to validate the survey-based measures of performance measure use. Four firms have uniform contracts for their managers with respect to the relative use of financial versus non-financial performance measures, although the number of performance measures in each category can vary between managers. However, I have no data with respect to the number of performance measures for each of the respondents in these four firms. One

firm has manager-specific contracts, which were provided to me ${ }^{5}$ As a result, archival data are available for 96 managers in five firms. After listwise deletion of the nine questionnaires with missing data, survey and proprietary data are available for 87 managers. 


\section{Measurement instruments}

The measurement instruments used in the questionnaire are either taken from previous accounting studies or are newly developed. More specifically, the instruments used to measure decision-making authority, task uncertainty, and environmental uncertainty are taken from previous accounting studies, while the instruments used to measure the performance measure characteristics and performance measure use are newly developed.

Since the data are obtained through questionnaires, all measures are perceptual measures. That is, each measure reflects the individual respondent's perception of the variable in question. As a result, the responses are individual-specific, not firm-specific. Although, I do not specifically label each variable, for example, perceived decision-making authority or perceived task uncertainty, it should be kept in mind that all variables are in fact perceptions.

Decision-making authority. I measure decision-making authority by taking the scale used by Gordon and Narayanan (1984). The instruments asks the respondents to indicate the extent to which they have decision-making authority with respect to (1) development of new products and services, (2) hiring and firing of personnel, (3) selection of large investments, (4) budget allocations, and (5) pricing decisions. A five-point fully anchored scale is used to indicate the level of authority. Confirmatory factor analysis shows that all five items load significantly on the latent variable decision-making authority. I compute the decision-making authority construct by summing and averaging the standardized scores of the five items.

Performance measure characteristics. To date no attempt has been made to measure the characteristics of performance measures. In order to measure the performance measure characteristics, I therefore develop new constructs. The survey questionnaire contains, for each type of performance measure, 15 statements concerning the performance measure characteristics. A five-point fully anchored scale is used to indicate the level of agreement with these statements. The 15 statements, listed in Table 2, are based on the literature with 
respect to the controllability principle (e.g., Merchant 1989) and the principal-agent model and are designed to measure the constructs sensitivity, controllability, and measurement accuracy. The statements relate to the extent to which each type of performance measure is influenced by (1) the manager's actions and (2) factors outside the control of the manager, as well as the extent to which the measure is objective and verifiable. A priori it is expected that items $a .-e$. will measure controllability, f.-k. sensitivity, and $l .-o$. measurement accuracy.

Insert Table 2 about here

Principal component analysis with oblique rotation reveals four factors with eigenvalues greater than 1, explaining $59 \%$ of the total variance. Table 2 shows how each of the 15 items load on the four factors. The results indicate that there are three 'independent' constructs, i.e., factor 1-3, while factor 4 seems to be a mixture of factor 1 and 3. Examining the items loading on factors 1-3 reveals that the items loading on factor 1 relate to the impact the manager has on performance, while the items loading on factor 2 and 3 relate to respectively the objectivity and verifiability of the measure and the impact of uncontrollable factors. In general, the principal component analysis seems to be consistent with the expectation that the 15 items contain the constructs sensitivity (factor 1), controllability (factor 3), and measurement accuracy (factor 2). The only item that does not load on one of the first three factors is item $g$. An explanation for this finding might be that this item is reverse coded.

I measure the constructs sensitivity, controllability, and measurement accuracy by summing and averaging, for each type of performance measure separately, the standardized scores of the items that relate to respectively factor 1 , factor 3 , and factor 2 . 
Task uncertainty. I construct the task uncertainty variable by taking the instrument developed by Withey et al. (1983), which contains nine statements with respect to the analyzability (complexity) and variability (diversity) of the respondent's tasks. A five-point fully anchored scale is used to indicate the level of agreement with each of these nine statements. Confirmatory factor analysis indicates that all nine items load significantly on the latent variable, although three items have low factor loadings. A principal component analysis with oblique rotation reveals an indication of multi-dimensionality. However, the factors identified do not correspond to the dimensions of analyzability and variability that are sometimes seen as important independent factors (see e.g., Brownell and Hirst 1986). Since the principal component analysis does not reveal clear independent factors and all items load significantly on the latent variable, I compute task uncertainty by summing and averaging the standardized scores of the nine items.

Environmental uncertainty. The environmental uncertainty variable is derived from the scales used by Govindarajan (1984) and Merchant (1990) and consists of five attributes with respect to the respondent's work environment. The five attributes relate to the behavior of (1) customers, (2) competitors, and (3) suppliers, as well as (4) technological developments and (5) political and/or legal changes. Ten items are used to indicate to what extent each of these five attributes are predictable and have on impact on the work and performance of the respondents. A six-point fully anchored scale is used, which consists of a five-point scale to indicate the extent of predictability and impact and an additional option that can be used to indicate that the specific factor is not part of the respondent's environment.

Similar to the way in which Khandwalla (1972) and Libby and Waterhouse (1996) measure competition, I compute the environmental uncertainty variable by multiplying, for each attribute, the ratings on impact by predictability and taking the square root of the product. $\mathrm{D}$ Confirmatory factor analysis indicates that all but one product term load 
significantly on the latent variable. The attribute 'political and/or legal changes' does not load on the above construct and is therefore deleted from the measurement instrument. As a result, I measure environmental uncertainty by summing and averaging the standardized scores of the remaining four attributes.

Performance measure use. The extent to which each type of performance measure is used in the evaluation and compensation of the managers is measured using eight items. These items, shown in Table 3, relate to the use of each type of performance measure for (1) evaluation purposes, (2) monetary compensation, and (3) non-monetary rewards. A five-point fully anchored scale is used to indicate the importance of each type of performance measure for performance evaluation and compensation purposes. Principal component analysis reveals one factor with an eigenvalue greater than one, explaining $58 \%$ of the total variance. I compute the construct performance measure use by summing and averaging the standardized scores of the eight items for each type of performance measure.

Insert Table 3 about here

To test whether these survey-based constructs of performance measure use are consistent with the relative reliance on financial performance measures (\%FPM) stated in the annual bonus contract, I split the sample into two groups of approximately equal size based on the median reported \%FPM. For each sub-sample, I compare the use of financial performance measures with the use of the two non-financial performance measures using a paired-sample t-test.

The results, shown in Table 4, indicate that for the 'low-\%FPM' sub-sample the use of financial performance measures is indeed significantly lower than the use of the non-financial performance measures (one-tail $\mathrm{p}<0.01$ ). For the 'high-\%FPM' sub-sample the use of 
financial performance measures is significantly higher than the use of the non-financial performance measures (one-tail $\mathrm{p}<0.01$ ). Further, for both sub-samples there is no significant difference between the use of the two non-financial performance measures. These results provide some evidence that the survey-based measures are consistent with the weights stated in the annual bonus contract.

Insert Table 4 about here

Previously, I stated that four firms have uniform annual bonus contracts with respect to the relative use of financial versus non-financial performance measures, although the number of performance measures in each category can vary between managers. To test whether respondents within each firm report firm-specific incentives, i.e., corporate policy, rather than individual-specific incentives, I examine the distribution of responses within each of these four firms. The results show that, although the mean response is consistent with corporate policy, there is no clustering of responses and there is significant variation in responses within each firm. These results suggest that the firms in question create individualspecific incentives and that the respondents report these individual-specific incentives.

Descriptive statistics for all variables are provided in Table 5

Insert Table 5 about here

\section{EMPIRICAL RESULTS}

The hypotheses stated in section II are tested by estimating the empirical model

presented in Figure 1 using Amos $4.0^{8}$ Because of sample size limitations, I estimate the empirical model for each type of performance measure separately. Furthermore, I treat all 
variables in the model as observed variables rather than latent variables. The significance levels reported in this section are based on bootstrapping (Noreen 1989; Mooney and Duval $1993)$

\section{Insert Figure 1 about here}

For presentation purposes, I discuss the empirical results by hypothesis. The empirical results with respect to the factors explaining the use of performance measures, i.e., hypotheses 1-2, are presented in Table 6.

\section{Hypotheses 1a-1c}

Hypothesis 1a predicts that decision-making authority has a positive effect on the use of financial performance measures. The empirical results, shown in Table 6, indicate that decision-making authority is positively related to the use of financial performance measures (one-tail $\mathrm{p}<0.05$ ), which provides support for hypothesis 1a. The effect of decision-making authority on the use of internal and external non-financial performance measures is unknown a priori, as reflected by the null-hypotheses $1 \mathrm{~b}$ and $1 \mathrm{c}$. The empirical results show that decision-making authority does not affect the use of either internal or external non-financial performance measures. Therefore, hypotheses $1 \mathrm{~b}$ and $1 \mathrm{c}$ are supported.

Insert Table 6 about here

\section{Hypotheses 2a(i)-2c(i)}

The performance measure characteristic sensitivity is hypothesized to have a positive effect on the use of the three types of performance measures. The empirical results show that 
sensitivity is positively related to the use of all three types of performance measures (one-tail $\mathrm{p}<0.01)$ and therefore provide strong support for hypotheses $2 \mathrm{a}(i), 2 \mathrm{~b}(i)$, and $2 \mathrm{c}(i)$.

\section{Hypotheses 2a(ii)-2c(ii)}

Hypotheses $2 \mathrm{a}(\mathrm{ii})-2 \mathrm{c}(\mathrm{ii})$ state that the use of performance measures increases with its controllability, as predicted by the controllability principle. Table 6 , however, indicates that these hypotheses are not supported by the data. The empirical results show that controllability is not related to the use of internal and external non-financial performance measures, while it is negatively related to the use of financial performance measures. This last finding is actually contrary to my expectations and I discuss some plausible explanations in the final chapter.

\section{Hypotheses 2a(iii)-2c(iii)}

The last performance measure characteristic that is expected to positively affect the use of the three types of performance measures is measurement accuracy. The empirical results show that measurement accuracy is positively related to the use of financial and internal non-financial performance measures (one-tail $\mathrm{p}<0.05$ ) but not related to the use of external non-financial performance measures. As a result, hypotheses $2 \mathrm{a}(\mathrm{iii})$ and $2 \mathrm{~b}(\mathrm{iii})$ are supported, while hypothesis $2 \mathrm{c}(\mathrm{iii})$ is not supported by the data.

Insert Table 7 about here

\section{Hypotheses 3a-3c}

The empirical results with respect to the effect of task uncertainty on the sensitivity of the three types of performance measures are summarized in Table 7 . The results provide strong support for hypotheses 3a-3c. That is, task uncertainty increases the sensitivity of financial performance measures (one-tail $\mathrm{p}<0.025$ ) and internal non-financial performance measures (one-tail $\mathrm{p}<0.01$ ) but it does not affect the sensitivity of external non-financial 
performance measures. Therefore, financial and internal non-financial performance measures become more useful as task uncertainty increases.

\section{Hypotheses 4a-4c}

Finally, hypotheses $4 \mathrm{a}-4 \mathrm{c}$ predict that the level of environmental uncertainty negatively affects the controllability of the three types of performance measures. The empirical results, presented in Table 8, provide strong support for these hypotheses. The analysis shows that environmental uncertainty is negatively related to the controllability of all three types of performance measures (one-tail $\mathrm{p}<0.01$ ). That is, the controllability decreases as environmental uncertainty increases.

Insert Table 8 about here

In summary, the empirical results first indicate that decision-making authority is positively related to the use of financial performance measures but not related to the use of the non-financial performance measures. Therefore hypotheses 1a-1c are supported. Second, sensitivity and measurement accuracy are the most important performance measure characteristics, with sensitivity being related to the use of all three types of performance measures and measurement accuracy being related to the use of financial and internal nonfinancial performance measures. The performance measure characteristic controllability, on the other hand, does not have the proposed positive effect on performance measure use. The only relationship that is significant shows an opposite effect, indicating that the use of financial performance measures is negatively related to their controllability. As a result, hypotheses $2 \mathrm{a}_{\mathrm{i}}, 2 \mathrm{a}_{\mathrm{iii}}, 2 \mathrm{~b}_{\mathrm{i}}, 2 \mathrm{~b}_{\mathrm{iii}}$, and $2 \mathrm{c}_{\mathrm{i}}$ are supported and hypotheses $2 \mathrm{a}_{\mathrm{ii}}, 2 \mathrm{~b}_{\mathrm{ii}}, 2 \mathrm{c}_{\mathrm{ii}}$, and $2 \mathrm{c}_{\mathrm{iii}}$ are not supported. Third, the results also provide evidence that task uncertainty increases the sensitivity of financial and internal non-financial performance measures, but is not related to 
the sensitivity of external non-financial performance measures. Therefore, hypotheses $3 a-3 c$ are supported, which suggests that the usefulness of financial and internal non-financial performance measures increases with task uncertainty. Finally, the controllability of all three types of performance measures decreases with increased environmental uncertainty, which lends support for hypotheses $4 \mathrm{a}-4 \mathrm{c}$. That is, the non-financial performance measures contain the same defects as the financial performance measures when environmental uncertainty is high. The results of the hypothesis testing are summarized in Table 9.

Insert Table 9 about here

\section{Sensitivity analysis and additional tests}

In the empirical analysis, I implicitly tested the prediction that uncertainty has an indirect effect, rather than a direct effect, on the use of performance measures. Simple correlation analysis shows that environmental uncertainty and the use of financial performance measures are positively related (one-tail $\mathrm{p}<0.01$ ) and that task uncertainty and the use of internal non-financial performance measures are positively related (one-tail $\mathrm{p}<0.025)$. To examine whether the relationship between the performance measure characteristics and the use of performance measures are due to the omission of the direct effect of uncertainty, I perform two tests.10 First, I incorporate the direct effects of environmental uncertainty and task uncertainty into the empirical model in Figure 1 with respect to the two types of performance measures. For both models, the direct effects of both types of uncertainty are not significant, while all other relationships are identical to those presented in the previous section. Second, I test whether the indirect model or the direct model, which is nested in the indirect model, has a better fit to the data. By constraining the relevant relationships to zero, I calculate the chi-square difference statistic between both 
models for the financial and internal non-financial performance measures. The chi-square difference statistics with respect to financial and internal non-financial performance measures are respectively 32.33 and 43.13 (for all $\mathrm{p}<0.01$ ), which indicates that for both types of performance measures the indirect model has a better fit to the data. As a result, the relationship between the performance measure characteristics and the use of performance measures is not due to the omission of a direct effect of uncertainty.

According to economic theory, organizations should simultaneously select organizational design variables, such as decision-making authority and the use of performance measures (e.g., Milgrom and Roberts 1995; Brickley et al. 1997). To examine whether decision-making authority and the use of performance measures are simultaneously determined, I estimate for each type of performance measure the non-recursive model presented in Figure 2. To allow the model to be estimated, the model includes, in addition to the hypotheses stated previously and the non-recursive nature, the relationship between environmental uncertainty and decision-making authority. Simple correlation analysis shows that environmental uncertainty and decision-making authority are positively related (one-tail $\mathrm{p}<0.05)$

Insert Figure 2 about here

The results related to the use of the non-financial performance measures indicate that decision-making authority has no effect on performance measure use and vice versa. The model with respect to the use of financial performance measures is not stable, implying that the empirical model is misspecified. From these results, I conclude that there is no evidence that decision-making authority and the use of performance measures are simultaneously determined, which is consistent with Nagar (1999). 
Finally, I split the model, presented in Figure 1, into two parts, i.e., (1) hypotheses 1a$2 \mathrm{c}$ and (2) hypotheses $3 \mathrm{a}-4 \mathrm{c}$, and estimate each part for all three performance measures simultaneously. In testing hypotheses $1 \mathrm{a}-2 \mathrm{c}, \mathrm{I}$ allow the performance measures to be simultaneously determined. The results from these additional tests are qualitatively similar to those presented in Tables 6-8.

\section{V.SUMMARY AND CONCLUSION}

This paper examines the role of performance measure characteristics in the design of incentive systems for subordinate managers. I find that environmental uncertainty decreases the controllability of financial performance measures, a relationship traditionally assumed in the literature. However, I further find that environmental uncertainty also decreases the controllability of internal non-financial and external non-financial performance measures. This indicates that the assumed defects of financial performance measures also apply to the non-financial performance measures. Interestingly, the degree of controllability does not have the proposed positive effect on the use of the three types of performance measures. Controllability of financial performance measures is negatively related to the use of these measures for incentive purposes. A plausible explanation for this relationship might be that the uncontrollables are a consequence of the manager's actions and are therefore informative. Another plausible explanation might be that superiors want their managers to be aware of the uncontrollables and take these into account when making decisions. However, I also find that controllability is not related to the use of the two non-financial performance measures, which cannot be explained by the above two reasons.

Further, the empirical findings indicate that, consistent with my expectations, the level of decision-making authority increases the use of financial performance measures and is not related to the use of the two non-financial performance measures. 
The degree to which the performance measures are measured in an accurate way seems to play a role in using performance measures for incentive purposes. I find that increased measurement accuracy increases the use of financial and internal non-financial performance measures. These results indicate that 'noise' due to the measurement process is relatively more important for using performance measures than 'noise' due to uncontrollable factors (controllability). A possible explanation for this finding might be that it is less costly for the firm to adjust for the extent to which they accurately measure performance than it is to adjust for uncontrollables. The fact that measurement accuracy does not affect the use of external non-financial performance measures, which are often measured by third parties, provides some evidence for this explanation.

The most important performance measure characteristic related to the use of performance measures is sensitivity. All three types of performance measures are affected by the extent to which the manager can influence them. These results provide strong evidence of the use of the informativeness principle by firms. That is, rather than using performance measures that are totally controllable (controllability principle), firms seem to choose performance measures that provide information about the manager's actions, even if these are partly uncontrollable (cf. Merchant 1989). In contrast to the behavioral-based literature, which generally states that the usefulness of financial performance measures decreases with increased task uncertainty, I find that task uncertainty increases the usefulness of financial and internal non-financial performance measures because it increases their sensitivity.

The results presented in this paper provide some directions for future research. First, the finding that controllability is not positively related to the use of performance measures deserves some additional attention. The accounting literature stresses the importance of the controllability principle and identifies the costs that are associated with the use of uncontrollable performance measures. However, if firms make efficient choices on average, 
then there must be increased benefits of not adjusting for the effects of uncontrollable factors. This is particularly interesting since the results indicate that 'noise' due to the measurement process does affect the use of performance measures for incentive purposes. Future research should address the costs and benefits associated with the adjustments made with respect to 'noise' due to the measurement process and 'noise' due to the effect of uncontrollable factors.

Second, in this study, I examine the effect of the performance measure characteristics sensitivity, controllability, and measurement accuracy. Although these characteristics dominate the theoretical literature, it is unlikely that these are the only (theoretically) relevant performance measure characteristics. One opportunity for future research is to identify additional characteristics that play a role in designing incentive systems and to examine how these characteristics change with specific contextual factors. 


\section{REFERENCES}

Anderson, T.W. 1957. Maximum Likelihood Estimates for a Multivariate Normal Distribution When Some Observations Are Missing. Journal of the American Statistical Association 52: 200-203.

Arbuckle, J.L., and W. Wothke. 1999. Amos 4.0 User's Guide. SmallWaters Corporation.

Atkinson, A.A., R. Balakrishnan, P. Booth, J.M. Cote, T. Groot, T. Malmi, H. Roberts, E. Uliana, and A. Wu. 1997. New Directions in Management Accounting Research. Journal of Management Accounting Research 9: 79-108.

Banker, R.D., and S.M. Datar. 1989. Sensitivity, Precision, and Linear Aggregation of Signals for Performance Evaluation. Journal of Accounting Research 27: 21-39.

Brickley, J.A, C.W. Smith, and J.L. Zimmerman. 1997. Managerial Economics and Organizational Architecture. Burr Ridge, IL: Richard D. Irwin.

Brownell, P. 1985. Budgetary Systems and the Control of Functionally Differentiated Organizational Activities. Journal of Accounting Research 23: 502-512.

Brownell, P., and M.K. Hirst. 1986. Reliance on Accounting Information, Budgetary Participation, and Task Uncertainty: Tests of a Three-Way Interaction. Journal of Accounting Research 24: 241-249.

Chenhall, R.H., and D. Morris. 1986. The Impact of Structure, Environment, and Interdependence on the Perceived Usefulness of Management Accounting Systems. The Accounting Review 61: 16-35.

Dillman, D.A. 1978. Mail and Telephone Surveys: The Total Design Method. New York: John Wiley \& Sons.

Feltham, G.A., and J. Xie. 1994. Performance Measure Congruity and Diversity in Multi-Task Principal/Agent Relations. The Accounting Review 69: 429-453. 
Fisher, J. 1995. Contingency-Based Research on Management Control Systems: Categorization by Level of Complexity. Journal of Accounting Literature 14: 24-53. Flannery, T.P., D.A. Hofrichter, and P.E. Platten. 1996. People, Performance, and Pay: Dynamic Compensation for Changing Organizations. The Hay Group: The Free Press. Galbraith, J.R. 1973. Designing Complex Organizations. Reading: Addison-Wesley.

Galbraith, J.R. 1977. Organization Design. Reading: Addison-Wesley.

Gordon, L.A., and V.K. Narayanan. 1984. Management Accounting Systems, Perceived Environmental Uncertainty and Organizational Structure: An Empirical Investigation. Accounting, Organizations and Society 9: 33-47.

Govindarajan, V. 1984. Appropriateness of Accounting Data in Performance Evaluation: An Empirical Investigation of Environmental Uncertainty as an Intervening Variable. Accounting, Organizations and Society 9: 125-135.

— , and A.K. Gupta. 1985. Linking Control Systems to Business Unit Strategy: Impact on Performance. Accounting, Organizations and Society 10: 51-66.

Grice, J.W., and R.J. Harris. 1998. A Comparison of Regression and Loading Weights for the Computation of Factor Scores. Multivariate Behavioral Research 33: 221-247.

Hartmann, F.G.H. 2000. The Appropriateness of RAPM: Toward the Further Development of Theory. Accounting, Organizations and Society 25: 451-482.

Hirst, M.K. 1983. Reliance on Accounting Performance Measures, Task Uncertainty and Dysfunctional Behavior: Some Extensions, Journal of Accounting Research 21: 596605.

Holmström, B. 1979. Moral Hazard and Observability. Bell Journal of Economics 10: 74-91.

Ittner, C.D., and D.F. Larcker. 1999. The Effects of Performance Measure Diversity on Incentive Plan Outcomes. Working Paper, University of Pennsylvania. 
— , and — 2000. Assessing Empirical Research in Managerial Accounting: A ValueBases Management Perspective. Journal of Accounting and Economics (forthcoming). —, , and M.V. Rajan. 1997. The Choice of Performance Measures in Annual Bonus Contracts. The Accounting Review 72: 231-255.

Khandwalla, P.N. 1972. The Effect of Different Types of Competition on the Use of Management Controls. Journal of Accounting Research 10: 275-285.

Lambert, R.A., and D.F. Larcker. 1987. An Analysis of the Use of Accounting and Market Measures of Performance in Executive Compensation Contracts. Journal of Accounting Research 25: 85-125.

— and - 1995. The Prospective Payment System, Hospital Efficiency, and Compensation Contracts for Senior-Level Hospital Administrators. Journal of Accounting and Public Policy 14: 1-31.

Larcker, D.F. 1981. The Perceived Importance of Selected Information Characteristics for Strategic Capital Budgeting Decisions. The Accounting Review 56: 519-538.

Libby, T., and J.H. Waterhouse. 1996. Predicting Change in Management Accounting Systems. Journal of Management Accounting Research 8: 137-150.

Locke, E.A., and G.P. Latham. 1990. A Theory of Goal Setting and Task Performance. Englewood-Cliffs: Prentice Hall.

Merchant, K.A. 1989. Rewarding Results: Motivating Profit Center Managers. Boston: Harvard Business School Press.

— 1990. The Effects of Financial Controls on Data Manipulation and Management Myopia. Accounting, Organizations and Society 15: 297-313.

—, W.A. Van der Stede, and L. Zheng. 2000. Disciplinary Constraints on the Advancement of Knowledge: The Case of Organizational Incentive Systems. Working Paper, University of Southern California. 
Milgrom, P., and J. Roberts. 1995. Complementarities and Fit: Strategy, Structure, and Organizational Change in Manufacturing. Journal of Accounting and Economics 19: 179-208.

Mooney, C.Z., and R.D. Duval. 1993. Bootstrapping: A Nonparametric Approach to Statistical Inference. Sage University Paper Series on Quantitative Applications in the Social Sciences. Newbury Park, CA: Sage.

Nagar, V. 1999. Organizational Design Choices in Retail Banking. Working Paper, University of Michigan Business School.

Noreen, E.W. 1989. Computer-Intensive Methods for Testing Hypotheses. New York: John Wiley \& Sons.

Sloan, R.G. 1993. Accounting Earnings and Top Executive Compensation. Journal of Accounting and Economics 16: 55-100.

Withey, M., R.L. Daft, and W.H. Cooper. 1983. Measures of Perrow's Work Unit Technology: An Empirical Assessment and a New Scale. Academy of Management Journal 26: 45-63. 
TABLE 1

Descriptive statistics of participating firms

\begin{tabular}{lll}
\hline Firm & Activity & \# of employees \\
\hline A & Provision of financial services & 1,690 \\
B & $\begin{array}{l}\text { Trade of machinery and provision of } \\
\text { technical services }\end{array}$ & \\
& C & \\
C & Provision of life and indemnity insurance & 1,275 \\
D & Trade of pharmaceutical products & 401 \\
E & Production of food products & 7,482 \\
F & Financial leasing & 354 \\
\hline
\end{tabular}


TABLE 2

Principal component analysis with oblique rotation of the 15 items related to the performance measure characteristics (1) sensitivity, (2) controllability, and (3) measurement accuracy based on 315 observations (only factor scores higher than 0.3 are shown)

Items

My performance expressed in xxx performance measures is strongly affected by

a. ...changes in economic conditions

$b$....decisions made in other parts of the organization

c. ...changes in the behavior of customers

$d$....changes in the behavior or strategies of suppliers

$e$...changes in the behavior or strategies of competitors

$f$. Whether I function well or not as a manager can be expressed accurately in xxx performance g. Many of the activities and tasks that I perform do not show up in xxx performance

h. If I perform well as a manager, it is directly reflected in better xxx performance

$i$. Working hard leads to better xxx performance

j. Devotion and effort in my job leads to better xxx performance

$k$. Providing effort in my job leads to better xxx performance

l. The measurement of xxx performance is objective and verifiable

$m$. The measurement of xxx performance is done by objective persons

$n$. An independent person verifies the measurement of xxx performance

$o$. The measurement of $x x x$ is predominantly of a quantitative nature
Factor 1 Factor 2 Factor 3 Factor 4

0.698

0.394

0.757

0.622

0.726

0.427

$-0.578$

0.791

$-0.734$

0.505

0.837

0.782

0.851

0.837

0.871

0.837

0.562

Eigenvalue

3.42

2.34

2.05

1.09 
TABLE 3

Questionnaire items related to the measurement of the use of performance measures for performance evaluation and compensation purposes

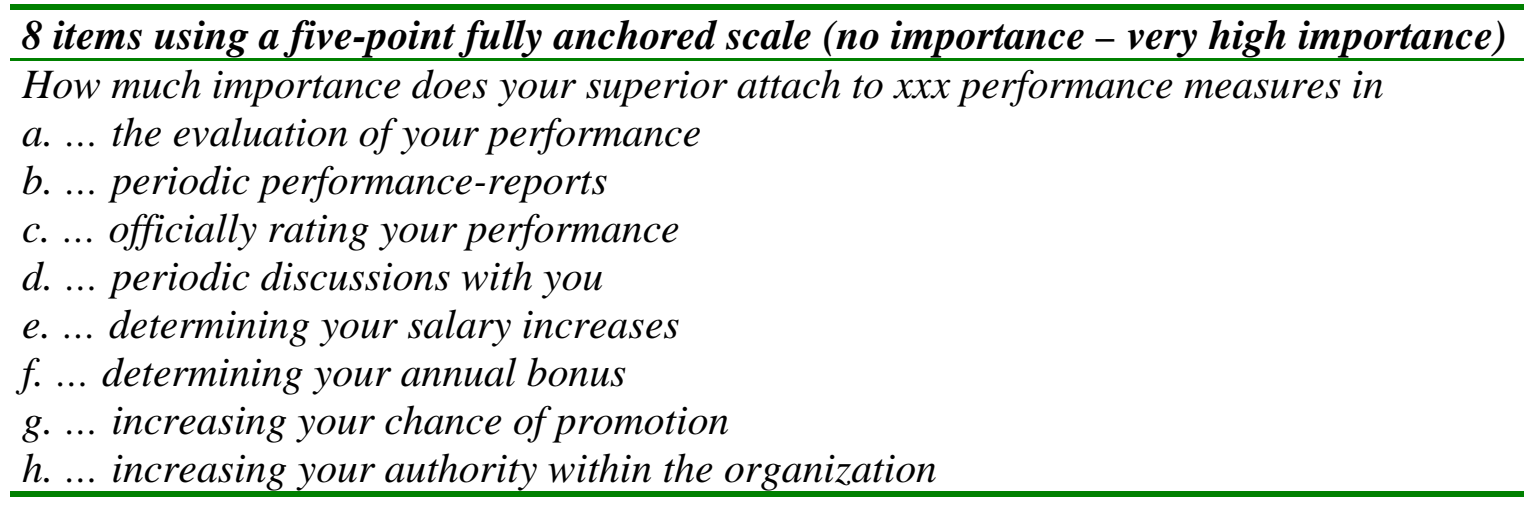


TABLE 4

Paired sample t-test with respect to differences between the use of financial and non-financial performance measures for groups of low and high reliance on financial performance measures in the annual bonus contract

\begin{tabular}{|c|c|c|c|c|}
\hline \multirow[b]{3}{*}{ Performance measure } & \multicolumn{4}{|c|}{$\begin{array}{l}\text { Relative reliance on financial performance measures } \\
\text { in annual bonus contract }\end{array}$} \\
\hline & \multicolumn{2}{|c|}{ Low } & \multicolumn{2}{|c|}{ High } \\
\hline & Mean use & Difference & Mean use & Difference \\
\hline Financial & -0.375 & & 0.388 & \\
\hline & & $-0.463^{* * *}$ & & $0.688^{* * *}$ \\
\hline Internal non-financial & 0.088 & & -0.300 & \\
\hline Financial & -0.375 & & 0.388 & \\
\hline & & $-0.331^{* * *}$ & & $0.565^{* * *}$ \\
\hline External non-financial & -0.044 & & -0.177 & \\
\hline Internal non-financial & 0.088 & & -0.300 & \\
\hline & & 0.132 & & -0.123 \\
\hline External non-financial & -0.044 & & -0.177 & \\
\hline
\end{tabular}

Notes:

${ }^{* * * * * *},{ }^{*},{ }^{\dagger}$ is significant at respectively the $1 \%, 2 \frac{1}{2} \%, 5 \%$, and $10 \%$ level (one-tailed). 
TABLE 5

Descriptive statistics of variables used $(n=105)$

\begin{tabular}{lcccc}
\hline Variable & Mean & Standard deviation & Actual range & Cronbach alpha \\
\hline Task uncertainty & 0 & 0.60 & $-1.22-1.54$ & 0.77 \\
Environmental uncertainty & 0 & 0.68 & $-3.32-1.48$ & 0.59 \\
Decision-making authority & 0 & 0.71 & $-1.82-1.49$ & 0.75 \\
Sensitivity FPM & 0 & 0.70 & $-1.73-1.83$ & 0.73 \\
Controllability FPM & 0 & 0.61 & $-1.41-1.64$ & 0.57 \\
Measurement accuracy FPM & 0 & 0.76 & $-1.98-1.34$ & 0.75 \\
Sensitivity INFPM & 0 & 0.76 & $-2.14-1.68$ & 0.81 \\
Controllability INFPM & 0 & 0.67 & $-1.43-1.98$ & 0.70 \\
Measurement accuracy INFPM & 0 & 0.77 & $-1.75-2.05$ & 0.77 \\
Sensitivity ENFPM & 0 & 0.78 & $-2.39-1.57$ & 0.83 \\
Controllability ENFPM & 0 & 0.65 & $-1.56-1.91$ & 0.65 \\
Measurement accuracy ENFPM & 0 & 0.77 & $-1.79-1.44$ & 0.78 \\
Use of FPM & 0 & 0.74 & $-2.11-1.59$ & 0.88 \\
Use of INFPM & 0 & 0.78 & $-2.31-1.56$ & 0.91 \\
Use of ENFPM & 0 & 0.77 & $-2.32-1.49$ & 0.90 \\
\hline Notes: & & & &
\end{tabular}


TABLE 6

Empirical results of the effects of decision-making authority, sensitivity, controllability, and measurement accuracy on the use of performance measures

\begin{tabular}{|c|c|c|c|}
\hline \multirow[b]{2}{*}{ Independent Variable } & \multicolumn{3}{|c|}{ Dependent Variable } \\
\hline & $\begin{array}{c}\text { Use of } \\
\text { Financial } \\
\text { Performance } \\
\text { Measures }\end{array}$ & $\begin{array}{c}\text { Use of } \\
\text { Internal } \\
\text { Non-financial } \\
\text { Performance } \\
\text { Measures }\end{array}$ & $\begin{array}{c}\text { Use of } \\
\text { External } \\
\text { Non-financial } \\
\text { Performance } \\
\text { Measures }\end{array}$ \\
\hline Decision-making Authority & $0.16^{*}$ & -0.09 & -0.08 \\
\hline Sensitivity $^{\mathrm{a}}$ & $0.30^{* * * *}$ & $0.48^{* * *}$ & $0.46^{* * *}$ \\
\hline Controllability $^{\mathrm{a}}$ & $-0.32^{* * *}$ & -0.09 & -0.09 \\
\hline Measurement Accuracy ${ }^{\mathrm{a}}$ & $0.16^{*}$ & $0.15^{*}$ & -0.07 \\
\hline Squared Multiple Correlation & 0.23 & 0.27 & 0.24 \\
\hline \multicolumn{4}{|c|}{$\begin{array}{l}\text { Notes: } \\
*_{* * * *}^{* * *},{ }^{*},{ }^{\dagger} \text { is significant at respectively the } 1 \%, 21 / 2 \%, 5 \% \text {, and } 10 \% \text { level (one-tailed) using } \\
\text { coefficient estimates and standard errors generated from } 500 \text { random bootstrap samples } \\
\text { (with replacement). } \\
\text { The performance measure characteristics relate to each type of performance measure. } \\
\text { b Parameters are maximum likelihood estimates. }\end{array}$} \\
\hline
\end{tabular}


TABLE 7

Empirical results of the effect of task uncertainty on the sensitivity of performance measures

\begin{tabular}{|c|c|c|c|}
\hline \multirow[b]{2}{*}{ Independent Variable } & \multicolumn{3}{|c|}{ Dependent Variable } \\
\hline & $\begin{array}{l}\text { Sensitivity of } \\
\text { Financial } \\
\text { Performance } \\
\text { Measures }\end{array}$ & $\begin{array}{l}\text { Sensitivity of } \\
\text { Internal } \\
\text { Non-financial } \\
\text { Performance } \\
\text { Measures }\end{array}$ & $\begin{array}{c}\text { Sensitivity of } \\
\text { External } \\
\text { Non-financial } \\
\text { Performance } \\
\text { Measures }\end{array}$ \\
\hline Task Uncertainty & $0.24^{* *}$ & $0.37^{* * *}$ & -0.10 \\
\hline Squared Multiple Correlation & 0.04 & 0.08 & 0.01 \\
\hline $\begin{array}{l}\text { Notes: } \\
\text { Not**** }{ }^{*},{ }^{*} \dagger \text { is significant at resp } \\
\text { coefficient estimates and sta } \\
\text { (with replacement). }\end{array}$ & $\begin{array}{l}y \text { the } 1 \%, 2 \\
\text { errors gene1 }\end{array}$ & $\begin{array}{l}\%, \text { and } 10 \% \text { 1 } \\
\text { om } 500 \text { rand }\end{array}$ & $\begin{array}{l}\text { one-tailed) usi } \\
\text { ootstrap samp }\end{array}$ \\
\hline
\end{tabular}


TABLE 8

Empirical results of the effect of environmental uncertainty on the controllability of performance measures

\begin{tabular}{|c|c|c|c|}
\hline \multirow[b]{2}{*}{ Independent Variable } & \multicolumn{3}{|c|}{ Dependent Variable } \\
\hline & $\begin{array}{l}\text { Controllability of } \\
\text { Financial } \\
\text { Performance } \\
\text { Measures }\end{array}$ & $\begin{array}{c}\text { Controllability of } \\
\text { Internal } \\
\text { Non-financial } \\
\text { Performance } \\
\text { Measures }\end{array}$ & $\begin{array}{c}\text { Controllability of } \\
\text { External } \\
\text { Non-financial } \\
\text { Performance } \\
\text { Measures } \\
\end{array}$ \\
\hline Environmental Uncertainty & $-0.38^{* * *}$ & $-0.28^{* * *}$ & $-0.23^{* * *}$ \\
\hline Squared Multiple Correlation & 0.18 & 0.08 & 0.06 \\
\hline $\begin{array}{l}\text { Votes: } \\
* * * * * *+{ }^{*},{ }^{*} \text { is significant at resp } \\
\text { coefficient estimates and sta } \\
\text { (with replacement). }\end{array}$ & $\begin{array}{l}\text { vely the } 1 \%, 2 \frac{1}{2} \% \\
\text { d errors generate }\end{array}$ & $\begin{array}{l}5 \% \text {, and } 10 \% \text { le } \\
\text { from } 500 \text { rando }\end{array}$ & $\begin{array}{l}\text { (one-tailed) using } \\
\text { bootstrap samples }\end{array}$ \\
\hline
\end{tabular}


TABLE 9

Results of hypothesis testing

\begin{tabular}{llcccc}
\hline & & & Expected & $\begin{array}{c}\text { Path } \\
\text { coefficients }\end{array}$ & Test results \\
\hline Relationship & & Hypothesis & sign & coefinted \\
DEC & $\rightarrow$ USE_FPM & $\mathrm{H} 1 \mathrm{a}$ & + & $0.16^{*}$ & Supported \\
DEC & $\rightarrow$ USE_INFPM & $\mathrm{H} 1 \mathrm{~b}$ & $?$ & -0.09 & Supported \\
DEC & $\rightarrow$ USE_ENFPM & $\mathrm{H} 1 \mathrm{c}$ & $?$ & -0.08 & Supported \\
SENS_FPM & $\rightarrow$ USE_FPM & $\mathrm{H} 2 \mathrm{a}_{\mathrm{i}}$ & + & $0.30^{* * *}$ & Supported \\
CON_FPM & $\rightarrow$ USE_FPM & $\mathrm{H} 2 \mathrm{a}_{\mathrm{ii}}$ & + & $-0.32^{* * *}$ & Not supported \\
ACC_FPM & $\rightarrow$ USE_FPM & $\mathrm{H} 2 \mathrm{a}_{\mathrm{iii}}$ & + & $0.16^{*}$ & Supported \\
SENS_INFPM & $\rightarrow$ USE_INFPM & $\mathrm{H} 2 \mathrm{~b}_{\mathrm{i}}$ & + & $0.48^{* * *}$ & Supported \\
CON_INFPM & $\rightarrow$ USE_FPM & $\mathrm{H} 2 \mathrm{~b}_{\mathrm{ii}}$ & + & -0.09 & Not supported \\
ACC_INFPM & $\rightarrow$ USE_INFPM & $\mathrm{H} 2 \mathrm{~b}_{\mathrm{iii}}$ & + & $0.15^{*}$ & Supported \\
SENS_ENFPM $\rightarrow$ USE_ENFPM & $\mathrm{H} 2 \mathrm{c}_{\mathrm{i}}$ & + & $0.46^{* * *}$ & Supported \\
CON_ENFPM & $\rightarrow$ USE_ENFPM & $\mathrm{H} 2 \mathrm{c}_{\mathrm{ii}}$ & + & -0.09 & Not supported \\
ACC_ENFPM & $\rightarrow$ USE_ENFPM & $\mathrm{H} 2 \mathrm{c}_{\mathrm{iii}}$ & + & -0.07 & Not supported \\
TU & $\rightarrow$ SENS_FPM & $\mathrm{H} 3 \mathrm{a}$ & + & $0.24^{* *}$ & Supported \\
TU & $\rightarrow$ SENS_INFPM & $\mathrm{H} 3 \mathrm{~b}$ & + & $0.37^{* * *}$ & Supported \\
TU & $\rightarrow$ SENS_ENFPM & $\mathrm{H} 3 \mathrm{c}$ & $?$ & -0.10 & Supported \\
EU & $\rightarrow$ CON_FPM & $\mathrm{H} 4 \mathrm{a}$ & - & $-0.38^{* * *}$ & Supported \\
EU & $\rightarrow$ CON_INFPM & $\mathrm{H} 4 \mathrm{~b}$ & - & $-0.28^{* * *}$ & Supported \\
EU & $\rightarrow$ CON_ENFPM & $\mathrm{H} 4 \mathrm{c}$ & - & $-0.23^{* * *}$ & Supported \\
\hline
\end{tabular}

Notes:

${ }^{* * *},{ }^{* *},{ }^{*},{ }^{\dagger}$ is significant at respectively the $1 \%, 21 / 2 \%, 5 \%$, and $10 \%$ level (one-tailed) using coefficient estimates and standard errors generated from 500 random bootstrap samples (with replacement).

${ }^{\text {a }}$ Parameters are maximum likelihood estimates. 
FIGURE 1

\section{Empirical model}

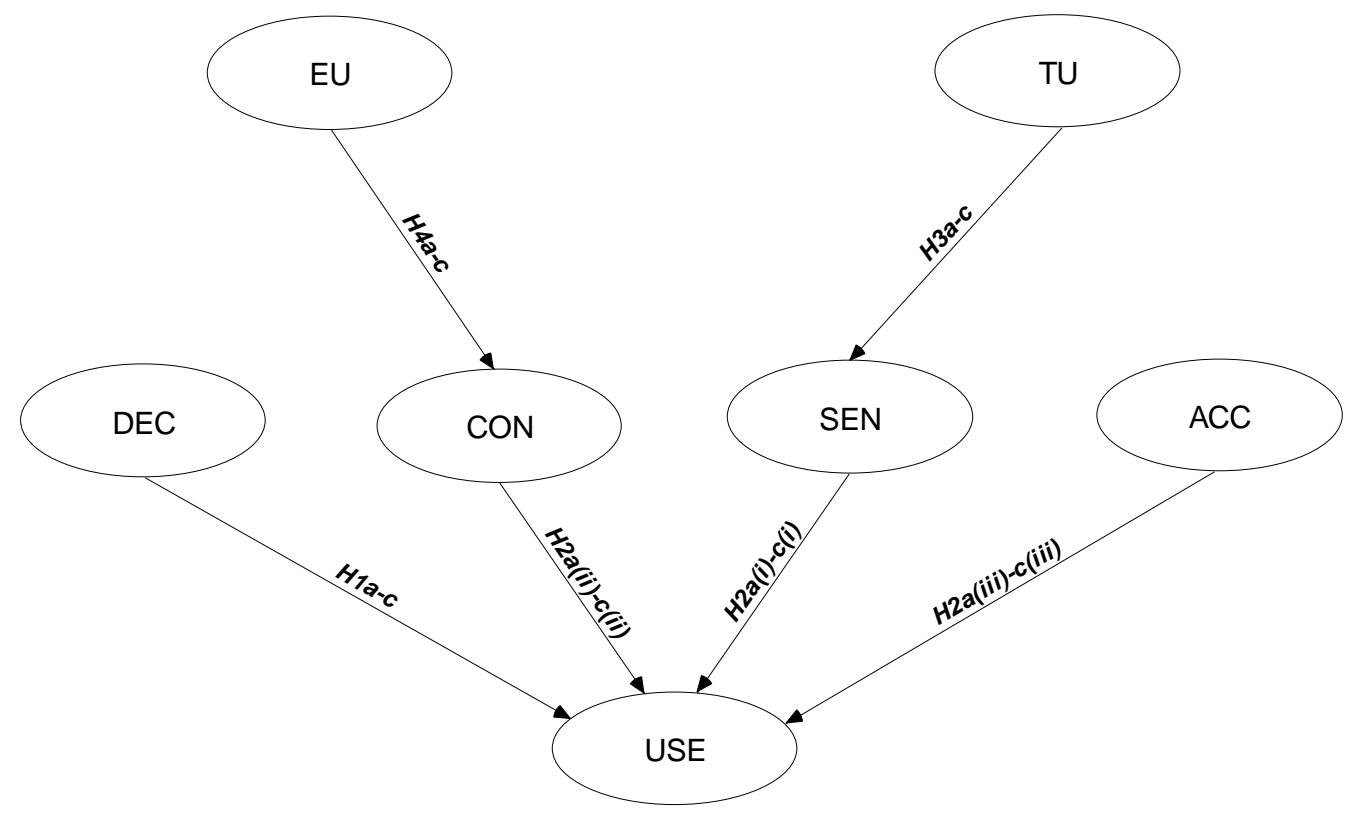

Notes:

${ }^{\mathrm{a}} \mathrm{EU}=$ environmental uncertainty;

$\mathrm{TU}=$ task uncertainty;

$\mathrm{DEC}=$ decision-making authority;

$\mathrm{CON}=$ controllability of performance measures;

SEN $=$ sensitivity of performance measures;

$\mathrm{ACC}=$ measurement accuracy of performance measures;

$\mathrm{USE}=$ use of performance measures. 
FIGURE 2

Non-recursive model

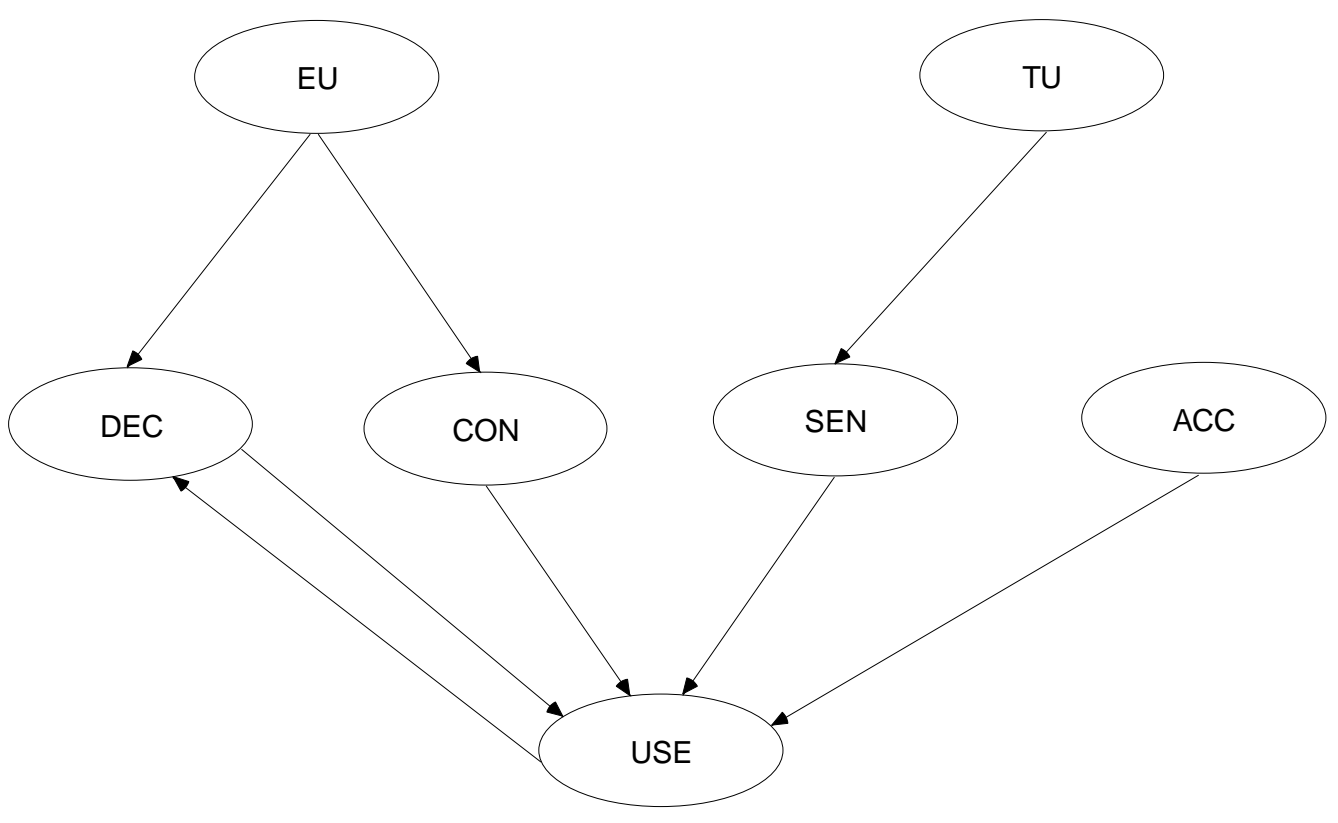

Notes:

${ }^{\mathrm{a}} \mathrm{EU}=$ environmental uncertainty;

$\mathrm{TU}=$ task uncertainty;

$\mathrm{DEC}=$ decision-making authority;

$\mathrm{CON}=$ controllability of performance measures;

SEN = sensitivity of performance measures;

$\mathrm{ACC}=$ measurement accuracy of performance measures;

$\mathrm{USE}=$ use of performance measures. 


\section{Endnotes:}

${ }^{1}$ All examples presented with respect to each type of performance measure are measures actually used for incentive purposes by the participating firms.

${ }^{2}$ Hirst (1983), for example, measures 'task uncertainty' by combining scales that reflect both task uncertainty and environmental uncertainty. Similarly, Brownell (1985) uses the functional area of managers to reflect differences in both task uncertainty and environmental uncertainty.

${ }^{3}$ The three studies are a (1) field study, (2) archival study, and (3) questionnaire study complemented with archival data. To date these studies are still in progress.

${ }^{4}$ The Hay-points are based on the Hay Guide Chart Profile Method, a system that compares the value of jobs based on multiple factors such as accountability and know-how (Flannery et al. 1996, 20). A weight greater than 400 relates to higher-level personnel.

${ }^{5}$ The archival data can be linked to the questionnaire data through codes. Each questionnaire contains a unique code that is printed on the final page of the questionnaire. The HR manager of each firm provides the archival data mentioning the codes in stead of the respondent's name, which does not violate the anonymity principle.

${ }^{6}$ In computing all constructs, I use unit-weighted average standardized scores because these have preferred psychometric properties relative to regression estimates of factor scores (Grice and Harris 1998).

${ }^{7}$ The scores for impact and predictability are such that higher scores for impact mean higher impact, while higher scores for predictability mean lower predictability. The logic underlying the multiplication is that given the impact of the attributes, increased unpredictability makes it more difficult to control for this impact, which increases uncertainty.

${ }^{8}$ Amos is short for Analysis of Moment Structures. Amos uses the general approach to data analysis known as structural equation modeling (Arbuckle and Wothke 1999).

${ }^{9}$ I also calculate full information maximum likelihood (FIML) estimates (Anderson 1957) using all 114 observations. The results (not reported) are identical to those presented in this paper.

${ }^{10}$ Especially the unexpected significant negative relationship between controllability and the use of financial performance measures might be due to an omitted variable problem. There is evidence that suggests that the use of financial controls increases with uncertainty (e.g., Khandwalla 1972; Simons 1987) and uncertainty might therefore be the omitted variable. 
${ }^{11}$ This relationship is to some extent consistent with the predictions made by organization theory, which states that organizations become more decentralized when the environment is more uncertain. 